\title{
Factors Related to Malnutrition in Children Under Five Years with Congenital Heart Disease
}

\author{
Amani Sakinah Augiani, ${ }^{1}$ Sri Endah Rahayuningsih, ${ }^{2}$ Dewi Marhaeni Diah Herawati ${ }^{3}$ \\ ${ }^{1}$ Faculty of Medicine Universitas Padjadjaran, ${ }^{2}$ Department of Child Health Faculty of Medicine \\ Universitas Padjadjaran/Dr. Hasan Sadikin General Hospital Bandung, Indonesia, ${ }^{3}$ Department of \\ Public Health Faculty of Medicine Universitas Padjadjaran
}

\begin{abstract}
Background: Congenital heart disease (CHD) is the most frequent type of heart disease that occurs in children. Children with CHD are more vulnerable to suffer impaired nutritional status related to morbidity and mortality. The nutritional status, however, may not be influenced only by CHD, but also by other factors.. The study was conducted to identify factors related to malnutrition in children with CHD

Methods: This cross-sectional study involved 86 children with CHD recruited from Dr. Hasan Sadikin General Hospital Bandung from October to November 2015. Data collected in this study were obtained by conducting anthropometric measurements, interviewed the parents (obstetric history, patient's medical history and socioeonomic status) and from medical records (the type and time of CHD diagnosis, other diseases that accompanied the CHD). The collected data were presented by frequency distribution.

Results: There were $46.5 \%$ patients who had nutritional disturbance. Malnutrition in males and patients with Tetralogy of Fallot were higher than other groups. Almost half patients with maternal history of passive smoking during pregnancy had nutritional disturbance. The most common disease found was diarrhea followed by lower respiratory infection. Percentage of normal children in low-income parents group was lower than the high-income group.

Conclusions: Nearly half of patients have nutritional disturbance. Percentage of nutritional disturbance in male was higher compared to female. Active and passive smokers, Tetralogi Fallot, diarrhea, lower respiratory infection and lower income were factors contributed to malnutrition. [AMJ.2017;4(1):111-7]
\end{abstract}

Keywords: Children, congenital heart disease, nutritional status

\section{Introduction}

Congenital heart disease (CHD) is a cardiovascular structural abnormality ${ }^{1}$ and is the most common heart disease in children, which affects between 3.7 and 17.5 per 1000 live births. ${ }^{2,3}$ Congenital heart disease also falls under the most frequently inherited disorders, encompassing one-third of all congenital abnormalities. ${ }^{3}$ It is a serious condition as it has significant effects on the rate of morbidity, mortality, and healthcare cost. ${ }^{4}$ Infants with CHD generally show symptoms shortly after birth, however, the remaining 25\%, are diagnosed in childhood. ${ }^{4}$

Children with CHD are more vulnerable to have poor nutritional status and experience decrease of growth trajectory. ${ }^{5,6}$ Some of the other factors that may influence a child's nutritional status beside CHD are age, gender, obstetrical history, illness. ${ }^{7,8}$ Hence, this study was conducted to identify factors related to malnutrition in children under five with CHD.

\section{Methods}

A descriptive quantitative study was carried out to 86 children with CHD and their parents who were seeking care in Outpatient Clinic of Pediatric Cardiology, Dr. Hasan Sadikin General Hospital Bandung from October to November 2015. The inclusion criteria of this study were patients with CHD $\leq 60$ months old. The exclusion criteria for this study were patients with CHD who had undergone surgical correction or parents who declined participating in this study. Ethical clearance of this study was obtained from Health Research

Correspondence: Amani Sakinah Augiani, Faculty of Medicine, Universitas Padjadjaran, Jalan Raya Bandung-Sumedang Km.21, Jatinangor, Sumedang, Indonesia, Phone: +6281210006284 Email: augianiamani@gmail.com 
Ethical Committee Dr. Hasan Sadikin General Hospital Bandung (No. LB.04.01/A05/ EC/382/IX/2015).

Data collection was begun by requesting the patient's parents to sign informed consent form. The parents were enquired about the patient's personal data (patient's name, medical record number, gender, and date of birth), obstetrical history (pregnancy and birth history, and risk factor during pregnancy), history of other diseases, and parental characteristic (educational level, income, and history of CHD or other heart disease). Diagnosis (type of CHD and age of patient when diagnosed) and history of other diseases were obtained from the patient's medical record with the approval of the parents. The patient's age when he or she was examined and first diagnosed were classified into birth (only for time of first diagnosed), neonate ( $\leq 1$ months), infant (1-24 months), and young child (24-60 months). ${ }^{9}$

Obstetrical history was obtained by interviewing the parents. The gestational age were classified into three groups consisted of pre-term ( $<37$ weeks), at term (37-41 6/7 weeks) and post-term ( $\geq 42$ weeks). ${ }^{10}$ Risk in pregnancy was divided into three groups consisted of active smoking, passive smoking, and alcohol consumption. The patient's birth weight were divided into low birth weight $(<2500$ gram $)$ and normal birth weight $(\geq 2500$ gram). ${ }^{11}$

History of other diseases were obtained from the patient's medical record and interviewed the parents about diarrhea, measles, lower respiratory tract infection, and/or other diseases experienced by the patients.

In addition to the data classifications, the education level of the patient's parents was divided into undergraduate, diploma, senior high school, junior high school and primary school The income of both parents was divided into two large groups bounded by IDR 1.131.862 which was the lowest regional minimum fee for West Java Province in 2015. The parents were also enquired about familial history of heart problems or/and CHD.

For the anthropometric measurements, the patient's body weight and length/height were measured. Weight measurements were recorded in kilograms $(\mathrm{kg})$ to the nearest 0.1 $\mathrm{kg}$ by digital pediatric scale (for $\leq 2$ years old children) and adult scale (for children $\geq 2$ years old). The scale has been calibrated with proper position of the patient. The measurement was done based on minimal clothing used by the patient.

Length/height measurements were recorded in centimeters $(\mathrm{cm})$ to the nearest 0.1 $\mathrm{cm}$. A device for the measurement of recumbent length was used to measure patients with body length $<85 \mathrm{~cm}$. This technique required two examiners to keep the patient in the correct position (face was upward with the crown of the head toward the fixed end of the board and vertical frankfurt plane, the body was parallel to the board, the shoulder were rested, the feet was upward and without shoes). Whereas, for patients with body height $>85 \mathrm{~cm}$, a microtoise was used instead. This technique was recorded in standing position, head looking straight with horizontal frankfurt plane, shoulder relaxed, legs extended with heels almost together. Shoulder, blades, buttocks and heels should

\section{Table 1 Gender and Age when Examined in Patients with Congenital Heart Disease based} on Nutritional Status

\begin{tabular}{|c|c|c|c|c|c|c|c|c|}
\hline \multirow{3}{*}{ Characteristics } & \multicolumn{6}{|c|}{ Nutritional Status } & \multirow{2}{*}{\multicolumn{2}{|c|}{$\begin{array}{c}\text { Total } \\
(n=86)\end{array}$}} \\
\hline & \multicolumn{2}{|c|}{$\begin{array}{l}\text { Normal } \\
(n=46)\end{array}$} & \multicolumn{2}{|c|}{$\begin{array}{l}\text { Wasted } \\
(\mathrm{n}=20) \\
\end{array}$} & \multicolumn{2}{|c|}{$\begin{array}{c}\text { Severely Wasted } \\
(n=20)\end{array}$} & & \\
\hline & $\mathbf{n}$ & $\%$ & $\mathbf{n}$ & $\%$ & $\mathbf{n}$ & $\%$ & $\mathbf{n}$ & $\%$ \\
\hline \multicolumn{9}{|l|}{ Gender } \\
\hline Male & 16 & 34.8 & 11 & 55 & 11 & 55 & 38 & 44.2 \\
\hline Female & 30 & 65.2 & 9 & 45 & 9 & 45 & 48 & 55.8 \\
\hline \multicolumn{9}{|l|}{ Age when examined } \\
\hline Neonate & 0 & 0 & 0 & 0 & 0 & 0 & 0 & 0 \\
\hline Infant & 13 & 22.8 & 13 & 22.8 & 31 & 54.4 & 57 & 66.3 \\
\hline Young Child & 15 & 51.7 & 7 & 24.1 & 7 & 24.1 & 29 & 33.7 \\
\hline
\end{tabular}


Table 2 Diagnosis Characteristics in Patients with Congenital Heart Disease Based on Nutritional Status

\begin{tabular}{|c|c|c|c|c|c|c|c|c|}
\hline \multirow{3}{*}{ Characteristics } & \multicolumn{6}{|c|}{ Nutritional Status } & \multirow{2}{*}{\multicolumn{2}{|c|}{$\begin{array}{c}\text { Total } \\
(n=86)\end{array}$}} \\
\hline & \multicolumn{2}{|c|}{$\begin{array}{l}\text { Normal } \\
(n=46)\end{array}$} & \multicolumn{2}{|c|}{$\begin{array}{l}\text { Wasted } \\
(n=20)\end{array}$} & \multicolumn{2}{|c|}{$\begin{array}{c}\text { Severely Wasted } \\
(\mathrm{n}=20)\end{array}$} & & \\
\hline & $\mathbf{n}$ & $\%$ & $\mathbf{n}$ & $\%$ & $\mathbf{n}$ & $\%$ & $\mathbf{n}$ & $\%$ \\
\hline \multicolumn{9}{|l|}{ Type of CHD* } \\
\hline Congenital Heart Disease & & & & & & & 38 & 44.2 \\
\hline Ventricular Septal Defect & 18 & 56.2 & 9 & 2.8 & 5 & 15.6 & 32 & 37.2 \\
\hline Patent Ductus Arteriosus & 12 & 63.2 & 3 & 15.8 & 4 & 21 & 19 & 22.1 \\
\hline Atrial Septal Defect & 7 & 53.3 & 2 & 16.7 & 3 & 25 & 12 & 14 \\
\hline Tetralogy of Fallot & 2 & 28.6 & 2 & 28.6 & 3 & 42.9 & 7 & 8.1 \\
\hline Pulmonary Stenosis & 3 & 100 & 0 & 0 & 0 & 0 & 3 & 3.5 \\
\hline Aortic Stenosis & 1 & 100 & 0 & 0 & 0 & 0 & 1 & 1.2 \\
\hline Transposition of Great Arteries & 0 & 0 & 1 & 100 & 0 & 0 & 1 & 1.2 \\
\hline$>1$ Type of CHD* & 3 & 27.3 & 3 & 27.3 & 5 & 45.4 & 11 & 12.8 \\
\hline \multicolumn{9}{|l|}{ Age when diagnosed } \\
\hline At birth & 6 & 13 & 3 & 15 & 0 & 0 & 9 & 10.5 \\
\hline Neonate & 4 & 8.7 & 3 & 15 & 2 & 10 & 9 & 10.5 \\
\hline Infant & 33 & 71.7 & 14 & 70 & 18 & 90 & 65 & 75.6 \\
\hline Young Child & 3 & 6.5 & 0 & 0 & 0 & 0 & 3 & 3.5 \\
\hline
\end{tabular}

touch the measurement board.

The interpretation of these anthropometric data in the form of World Health Organization (WHO) z-score value was obtained. The result of this interpretation was divided into six groups consist of obese (above 3 ), overweight (above 2), risk of overweight (above 1), normal (above 1 to below -1), wasted (below -2 ), and severely wasted (below -3).12 The collected data were analyzed and presented by frequency distribution in the form of tables.

\section{Results}

Of 86 patients, more than half, were patients with normal nutritional status. Only fifth were severely wasted and wasted, respectively. There were no patients in this study who were obese, overweight, and risk of overweight status. (Table 1).

The number of female patients was higher than males. (Table 1). However, the percentage of patient with wasted and severely wasted status was higher in male patients compared to females. Infant group had higher percentage compared to young child group. This group had higher malnutrition cases compared to young child group. During the period of the study, there was no meonates who visited the hospital for seeking care.

The most common type of CHD are Ventricular Septal Defect (VSD), Patent Ductus Arteriosus (PDA), Atrial Septal Defect (ASD) and Tetralogy of Fallot (TOF), respectively (Table 2). The highest percentage of nutritional disturbance was in the group of patient with TOF. The peak age when diagnosed was in infant period consisted of 75 out of 86 patients $(75.6 \%)$.

For the history of gestational age, term patients $(73.9 \%)$ were found with higher proportion of normal nutritional status patients than postterm $(0.02 \%)$ and preterm patients $(23.9 \%)$ (Table 3). There was no patient with maternal history of alcohol consumption during pregnancy. Only 2 out of 86 were patients with maternal history of active smoking during pregnancy. Both of them were having normal nutritional status. There were 49 out of 86 patients with maternal history of passive smoking. More than half patients in this group were classified 
Table 3 Obstetrical History and Risk Factor in Patients with Congenital Heart Disease based on Nutritional Status

\begin{tabular}{|c|c|c|c|c|c|c|c|c|}
\hline \multirow{3}{*}{ Characteristics } & \multicolumn{6}{|c|}{ Nutritional Status } & \multirow{2}{*}{\multicolumn{2}{|c|}{$\begin{array}{c}\text { Total } \\
(\mathrm{n}=\mathbf{8 6})\end{array}$}} \\
\hline & \multicolumn{2}{|c|}{$\begin{array}{l}\text { Normal } \\
(n=46)\end{array}$} & \multicolumn{2}{|c|}{$\begin{array}{l}\text { Wasted } \\
(n=20)\end{array}$} & \multicolumn{2}{|c|}{$\begin{array}{c}\text { Severely Wasted } \\
(n=20)\end{array}$} & & \\
\hline & $\mathbf{n}$ & $\%$ & $\mathbf{n}$ & $\%$ & $\mathbf{n}$ & $\%$ & $\mathbf{n}$ & $\%$ \\
\hline \multicolumn{9}{|l|}{ Gestational Age } \\
\hline Postterm & 1 & 2.2 & 1 & 5 & 1 & 5 & 3 & 3.5 \\
\hline Term & 34 & 73.9 & 13 & 65 & 12 & 60 & 59 & 68.6 \\
\hline Preterm & 11 & 23.9 & 6 & 30 & 7 & 35 & 24 & 27.9 \\
\hline \multicolumn{9}{|c|}{ Risk Factor during Pregnancy } \\
\hline Passive smoking & 26 & 53.1 & 11 & 22.4 & 12 & 24.4 & 49 & 57 \\
\hline Active Smoking & 2 & 100 & 0 & 0 & 0 & 0 & 2 & 2.3 \\
\hline Alcohol consumption & 0 & 0 & 0 & 0 & 0 & 0 & 0 & 0 \\
\hline \multicolumn{9}{|l|}{ Birth Weight } \\
\hline Normal Birth Weight & 32 & 69.6 & 15 & 75 & 12 & 60 & 59 & 68.6 \\
\hline Low Birth Weight & 14 & 30.4 & 5 & 25 & 8 & 40 & 27 & 31.4 \\
\hline
\end{tabular}

as normal. Patients with history of normal birth weight had higher percentage of normal status $(69.6 \%)$ compared to patients with low birth weight history $(30.4 \%)$.

The most common other diseases were diarrhea (65.1\%), with more than half of total patients wasted and severely wasted (Table 4). Patients with lower respiratory infection had the lowest percentage of patient with normal status. Two third of all patients with measles mitral or tricuspid regurgitation had normal nutritional status. All of the patients in this study who had hernia, rubella syndrome, epilepsy, aplastic anemia, and other congenital abnormalities also had normal nutritional status.

Table 4 Other Diseases Accompanied Patients with Congenital Heart Disease based on Nutritional Status

\begin{tabular}{|c|c|c|c|c|c|c|c|c|}
\hline \multirow{3}{*}{ Characteristics } & \multicolumn{6}{|c|}{ Nutritional Status } & \multirow{2}{*}{\multicolumn{2}{|c|}{$\begin{array}{c}\text { Total } \\
(\mathrm{n}=\mathbf{8 6})\end{array}$}} \\
\hline & \multicolumn{2}{|c|}{$\begin{array}{l}\text { Normal } \\
(n=46)\end{array}$} & \multicolumn{2}{|c|}{$\begin{array}{c}\text { Wasted } \\
(\mathrm{n}=20)\end{array}$} & \multicolumn{2}{|c|}{$\begin{array}{c}\text { Severely } \\
\text { Wasted } \\
(n=20)\end{array}$} & & \\
\hline & $\mathbf{n}$ & $\%$ & $\mathbf{n}$ & $\%$ & $\mathbf{n}$ & $\%$ & $\mathbf{n}$ & $\%$ \\
\hline Diarrhea & 27 & 48.2 & 15 & 26.8 & 14 & 25 & 56 & 65.1 \\
\hline Lower Respiratory Tract Infection & 17 & 47.2 & 5 & 13.9 & 14 & 38.9 & 36 & 41.8 \\
\hline Measles & 4 & 66.7 & 1 & 16.7 & 1 & 16.7 & 6 & 7 \\
\hline Mitral/tricuspid Regurgitation & 2 & 66.7 & 0 & 0 & 1 & 33.3 & 3 & 3.5 \\
\hline Hernia & 2 & 100 & 0 & 0 & 0 & 0 & 2 & 2.3 \\
\hline Rubella syndrome & 2 & 100 & 0 & 0 & 0 & 0 & 2 & 2.3 \\
\hline Epilepsy & 1 & 100 & 0 & 0 & 0 & 0 & 1 & 1.2 \\
\hline Aplastic Anaemia & 1 & 100 & 0 & 0 & 0 & 0 & 1 & 1.2 \\
\hline Other Congenital Malformation & 1 & 100 & 0 & 0 & 0 & 0 & 1 & 1.2 \\
\hline
\end{tabular}


Table 5 Parental Characteristics of Patients with Congenital Heart Disease based on Nutritional Status

\begin{tabular}{|c|c|c|c|c|c|c|c|c|}
\hline \multirow{3}{*}{ Characteristics } & \multicolumn{6}{|c|}{ Nutritional Status } & \multirow{2}{*}{\multicolumn{2}{|c|}{$\begin{array}{c}\text { Total } \\
(\mathrm{n}=\mathbf{8 6})\end{array}$}} \\
\hline & \multicolumn{2}{|c|}{$\begin{array}{l}\text { Normal } \\
(n=46)\end{array}$} & \multicolumn{2}{|c|}{$\begin{array}{l}\text { Wasted } \\
(\mathrm{n}=20)\end{array}$} & \multicolumn{2}{|c|}{$\begin{array}{l}\text { Severely Wasted } \\
(n=20)\end{array}$} & & \\
\hline & $\mathbf{n}$ & $\%$ & $\mathbf{n}$ & $\%$ & $\mathbf{n}$ & $\%$ & $\mathbf{n}$ & $\%$ \\
\hline \multicolumn{9}{|l|}{ Education level of parents* } \\
\hline$U-U$ & 1 & 2.2 & 0 & 0 & 1 & 5 & 2 & 2.3 \\
\hline U-SHS & 5 & 13 & 0 & 0 & 4 & 20 & 9 & 10.5 \\
\hline D-D & 1 & 2.2 & 0 & 0 & 0 & 0 & 1 & 1.2 \\
\hline D-SHS & 3 & 6.5 & 2 & 10 & 4 & 20 & 9 & 10.5 \\
\hline SHS-SHS & 17 & 36.9 & 4 & 20 & 3 & 15 & 24 & 27.9 \\
\hline SHS-JHS & 8 & 17.4 & 8 & 40 & 1 & 5 & 15 & 17.4 \\
\hline JHS-JHS & 3 & 6.5 & 4 & 20 & 3 & 15 & 12 & 13.9 \\
\hline JHS-JHS & 5 & 13 & 2 & 10 & 2 & 10 & 9 & 10.5 \\
\hline PS-PS & 3 & 6.5 & 0 & 0 & 2 & 10 & 5 & 5.8 \\
\hline \multicolumn{9}{|l|}{ Income of parents } \\
\hline$<$ IDR 1.131.862,00 & 12 & 26.1 & 8 & 40 & 9 & 45 & 29 & 33.7 \\
\hline >IDR1.131.862,00 & 34 & 73.9 & 12 & 60 & 11 & 55 & 57 & 66.3 \\
\hline \multicolumn{9}{|l|}{ History of CHD in parents } \\
\hline Present & 1 & 50 & 1 & 50 & 0 & 0 & 2 & 3.5 \\
\hline Not Present & 45 & 54.2 & 19 & 22.9 & 20 & 24.1 & 84 & 96.5 \\
\hline
\end{tabular}

Patients with parent's educational level both graduated from Senior High School (SHS) were the most prevalent $(27.9 \%)$ and also had the highest percentage of patients with normal nutritional status (36.9\%) (Table 5). Patients with low-income parents (26.1\%) also had lower percentage of normal patients compared to patients with higher income parents $(73.9 \%)$. There were only 2 out of 86 patients in this study with parental history of CHD and/or other heart disease. From 84 patients without parental history, 54.2\% patients had normal nutritional status.

\section{Discussion}

This study revealed that the percentage of patient with normal nutritional status was slightly higher than patients with wasted and severely wasted status. This finding was different from the previous studies which stated that children with CHD were more vulnerable to experience nutritional disturbance. ${ }^{5,6}$ Although the proportion of normal patient was higher, almost all of the patient in this group had low z-score (below 0 or below -1).

In this study, the number of female patients were higher than the number of male patients. However, nutritional impairment was more prevalent in male patients. Previous study proved that male patients were more susceptible to have nutritional disturbance. ${ }^{8}$ The previous study concluded that the most frequently encountered types of CHD were ASD, VSD, PDA, PS, TOF, COA, TGA, and AS. ${ }^{1}$ According to the data obtained in this study, the type of CHD are VSD (32\%), PDA (19\%), ASD (12\%), and TOF (7\%), PS (3.5\%), AS (1.2\%), and TGA (1.2\%). This was consistent with previous study that claimed all of the above CHD are indeed included in the eight most common types of CHD. ${ }^{1}$

Previous study has shown that infants with CHD generally exhibit symptoms at birth, however, about $25 \%$ are only diagnosed in childhood. ${ }^{4}$ In this study, the child's age when first diagnosed peaked in the age group 
of infant $(75.6 \%)$. There is no patient that diagnosed after the age of 36 months. It can be deduced that CHD is generally detected early but it is estimated that there are several driving factors which may influence the delay in the detection of CHD in developing countries such as Indonesia. This may also produce difference in research results as compared to developed countries.

Previous study state that CHD patients hold better prospects if diagnosed and treated earlier. ${ }^{13}$ Based on this study, the distribution of each age group is dominated by a group of diagnosed at infant period $(75.6 \%)$, with the proportion of normal status $(71.7 \%)$. The difference between the result of this study and the previous one may be caused by most patients diagnosed in infant period.

Previous studies revealed about irrespective of CHD that there are other factors that may influence the nutritional status. For instance, age, gender, prenatal conditions, gestational age, birth weight, diseases, parents education and income. ${ }^{7,8}$

In general, children with CHD who had gestational age approaching 40 months were considered to have good outcomes. ${ }^{8}$ In this study, percentage of normal children with history of term gestational age $(73.9 \%)$ were much higher than preterm $(23.9 \%)$ and postterm $(2.2 \%)$ group. Children with a history of low birth weight were more inclined to have impaired nutritional status. ${ }^{14}$ Patients with history of low birth weight had lower percentage of normal status $(30.4 \%)$ compared to patients with normal birth weight history $(69.6 \%)$.

Mothers who smoked and consumed alcohol during pregnancy increase the risks of malnutrition in their child. ${ }^{8}$ None of the patient's mothers consumed alcohol in this study. However, there were two active smokers and 49 passive smokers. From 49 mothers who smoked passively, there was $53.1 \%$ of the patients who have normal nutritional status, $22.4 \%$ wasted, and $24.4 \%$ severely wasted. The difference between the result of this study may be caused by unknown factors that affect the patient during antenatal period.

Nutritional disorders in children may occur both primarily and secondarily. Primary nutritional disorder is one of the most basic types of disorders, and is mainly caused by nutrients insufficiency. ${ }^{5}$ Secondary nutritional disorder is the nutritional disorder caused by certain diseases, such as CHD, diarrhea, malaria, measles, and lower respiratory tract infection. ${ }^{15}$ In this study, the most prevalent other diseases were diarrhea, followed by lower respiratory infection.

Children with parents who have lower education and socioeconomic level have higher tendencies to suffer malnourishment. ${ }^{8}$ There were some variations of the patients' nutritional status based on the educational level of the parents. In this study, patients with parents who earn less hold the lower percentage of the patient with normal status compared to patient with parents who were earning more. The results showed consistencies with the previous study.

The etiology of CHD was still remain unknown. ${ }^{2}$ Previous study stated that CHD was a result of genetic and environmental factors. ${ }^{2}$ There was only two patients in this study with parent's history of CHD or other heart problems. One patient was with normal status and one patient was with wasted status.

Most of the results in this study were consistent to the previous studies about CHD and nutritional status, even though there were some differences in the result obtained. Unfortunately, there were certain limitations in this study. There was a recall bias of some data obtained from the patient's parents.

It can be concluded that nearly half of patients with CHD have malnutrition status (wasted and severe wasted, respectively). Percentage of wasted and severe wasted in male patients was higher than female patients. Most of the patients were diagnosed during infant. Active and passive smokers, Tetralogi Fallot, diarrhea, lower respiratory infection and lower income were factors that suspected to contribute to malnutrition in CHD patients.

\section{References}

1. Zheng JY, Tian HT, Zhu ZM, Li B, Han L, Jiang SL, et al. Prevalence of symptomatic congenital heart disease in Tibetan school children. Am J Cardiol. 2013;112(9):1468-70.

2. Marelli AJ, Mackie AS, Ionescu-Ittu R, Rahme E, Pilote L. Congenital heart disease in the general population changing prevalence and age distribution. Circulation. 2007;115(2):163-72.

3. Van Der Linde D, Konings EE, Slager MA, Witsenburg M, Helbing WA, Takkenberg JJ, et al. Birth prevalence of congenital heart disease worldwide: a systematic review and meta-analysis. J Am Coll Cardiol. 2011;58(21):2241-7.

4. AHA. Heart disease and stroke statistics-2015 update: a report from the 
American Heart Association. Circulation. 2015;131(4):29-322.

5. Sjarif DR, Anggriawan SL, Putra ST, Djer MM. Anthropometric profiles of children with congenital heart disease. Med J Indonesia. 2011;20(1):40-5.

6. Daymont C, Neal A, Prosnitz A, Cohen MS. Growth in children with congenital heart disease. J Pediatr. 2013;131(1):236-42.

7. Cnota JF, Gupta R, Michelfelder EC, Ittenbach RF. Congenital heart disease infant death rates decrease as gestational age advances from 34 to 40 weeks. J Pediatr. 2011;159(5):761-5.

8. De Lange JC. Factors contributing to malnutrition in children 0-60 months admitted to hospitals in the Northern Cape [dissertation]. Bloemfontein: University of the Free State Bloemfontein; 2012.

9. Knoppert D, Reed M, Benavides S, Totton J, Hoff D, Moffett B, et al. Paediatric age categories to be used in differentiating between listing on a model essential medicines list for children. [Online Journal] 2007 [cited 2016 January 13] Available from http://archives.who.int.

10. Fleischman AR, Oinuma M, Clark SL.
Rethinkingthedefinition of termpregnancy. Obstet Gynecol. 2010;116(1):136-9.

11. Onis M, Dewey KG, Borghi E, Onyango AW, Blössner M, Daelmans B, et al. The World Health Organization's global target for reducing childhood stunting by 2025 : rationale and proposed actions. Matern Child Nutr. 2013;9(Suppl2):6-26.

12. Onis M. WHO child growth standards: length/height-for-age, weight-for-age, weight-for-length, weight-for-height and body mass index-for-age. Geneva: World Health Organization; 2006.

13. Dawson AL, Cassell CH, Riehle-Colarusso T, Grosse SD, Tanner JP, Kirby RS, et al. Factors associated with late detection of critical congenital heart disease in newborns. Pediatrics. 2013;132(3):604-11.

14. Sarni RO, Carvalho MdFC, do Monte CM, Albuquerque ZP, Souza FI. Anthropometric evaluation, risk factors for malnutrition, and nutritional therapy for children in teaching hospitals in Brazil. J Pediatr (Rio J). 2009;85(3):223-8.

15. Shrivastava S. Malnutrition in congenital heart disease. Indian Pediatr. 2008;45(7):535-46. 